\title{
Sustainability Assessment of Advanced Machining Technologies
}

\author{
Luka Sterle - Damir Grguraš - Matjaž Kern - Franci Pušavec* \\ University of Ljubljana, Faculty of Mechanical Engineering, Slovenia
}

Efficient cooling and lubrication techniques are required to obtain sustainable machining of difficult-to-cut materials, which are the pillars of aerospace, automotive, medical and nuclear industries. Cryogenic machining with the assistance of lubricated Liquid Carbon Dioxide $\left(\mathrm{LCO}_{2}\right)$ is a novel approach for sustainable manufacturing without the use of harmful water-based metalworking fluids (MWFs). In case of unavoidable use of MWFs under high pressure, such as turning finishing processes of difficult-to-cut materials, the pulsating high pressure delivery of MWFs prolongs the tool life and enables the control over chip length to prevent surface damage of high value-added parts. In this paper, sustainability assessment of both advanced principles was carried out, considering overall costs and operational safety. Experimental tests were executed on difficult-to-cut materials in comparison to conventional flood lubrication. For both techniques, longer tool life compared to flood lubrication was observed additional cleaner production and higher part quality led to reduced long-term overall costs. These advanced machining technologies are also operation safe, proving to be a sustainable alternative to conventional machining.

Keywords: cryogenic machining, high pressure machining, sustainability, cost assessment, risk assessment

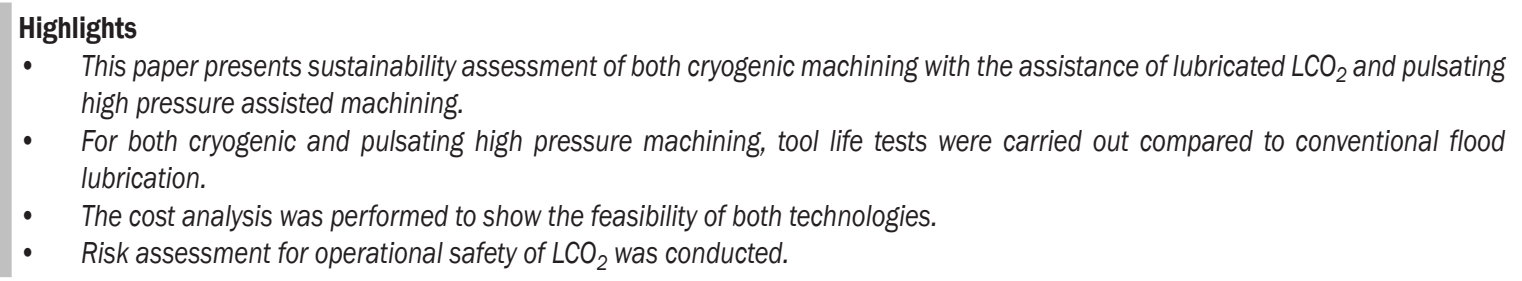

\section{O INTRODUCTION}

Machining present an important step in production to achieve the final shape of a product. Although additive manufacturing technologies aim to reduce the need for material removal by cutting, demanded dimensional and surface tolerances are mainly obtainable by machining processes. Furthermore, the global consumption of natural resources and the resulting pollution are leading factors for development of sustainable technologies, which can improve machining performance on economic, social and environmental levels.

The use of metalworking fluids (MWFs) in machining processes aims to improve machinability through prolonged tool life, improved surface integrity and chip evacuation. However, their use is correlated to environmental and health hazards and can present up to $17 \%$ of total manufacturing costs [1]. Dry cutting and Minimum Quantity Lubrication (MQL) are alternatives to conventional flood lubrication, but their application is limited, especially when difficult-to-cut materials are considered [1] to [3]. These materials, namely titanium- and nickelbased alloys are known for their high temperature resistance, high ductility and low temperature conductivity, thus resulting in poor machining performance. To counteract these effects, while offering a cleaner and safer approach of cooling and lubrication, cryogenic machining has been under development in the last decade [4] and [5]. The most used cryogenic medium was Liquid Nitrogen $\left(\mathrm{LN}_{2}\right)$, which exists in liquid state at $-195.8{ }^{\circ} \mathrm{C}$ and is delivered as such into the cutting zone, offering cooling mechanisms without lubrication. Moreover, due to its low temperature, lubricant cannot be added to the $\mathrm{LN}_{2}$ without freezing [6]. In addition, the cooling capability of $\mathrm{LN}_{2}$ is inferior to Liquid Carbon Dioxide $\left(\mathrm{LCO}_{2}\right)$ [7]. Low temperature of the $\mathrm{LN}_{2}$ is also its disadvantage; therefore, it's delivery through spindle/turret is challenging and risky, the $\mathrm{LN}_{2}$ leakage can cause serious damage to spindle/turret mechanics. Although it presents a cleaner alternative, the drawbacks of the $\mathrm{LN}_{2}$ prevent its wider use in industrial sector.

Machining with the assistance of $\mathrm{LCO}_{2}$ is thus becoming the focus of cryogenic machining research. The cooling mechanism here is different to liquid nitrogen; $\mathrm{LCO}_{2}$ is in liquid state at 57 bar and $20^{\circ} \mathrm{C}$. Due to the decrease of the saturation pressure upon exiting the nozzle, the $\mathrm{LCO}_{2}$ vaporizes and expands, absorbing heat from the surroundings. If the amount of $\mathrm{LCO}_{2}$ is sufficient, the micro-region is cooled down to the boiling point of $\mathrm{CO}_{2},-78.5^{\circ} \mathrm{C}$ [6] and [8]. This phase change (from liquid to gas) is shown in Fig. 1. 


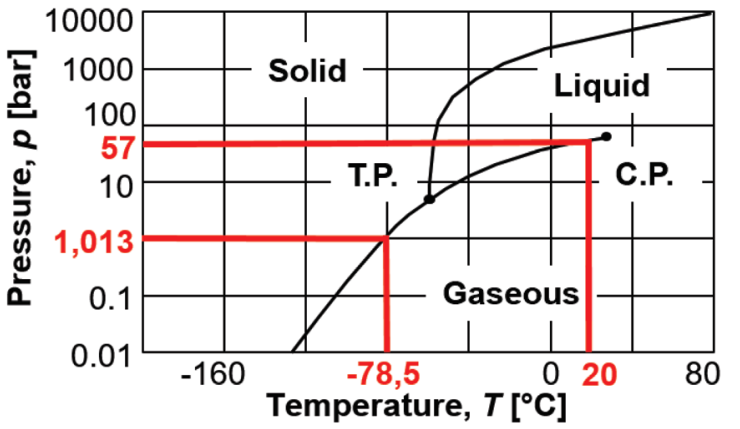

Fig. 1. $P$-T phase diagram of $\mathrm{CO}_{2}$

As the $\mathrm{LCO}_{2}$ is at room temperature right up to the exiting point, it can transport lubrication media with it [9]. This combination can also be denoted as $\mathrm{LCO}_{2}+\mathrm{MQL}$, as the two principles are combined. State-of-the-art $\mathrm{LCO}_{2}$ assisted machining shows promising results in terms of prolonged tool life [10] to [17], improved surface integrity [11], [13], [14], [17] and [20], lower cutting forces [13], [14], and [16] and reduced cutting temperatures compared to MQL and/ or dry machining [10], [11], [16] and [18]. However, the $\mathrm{LCO}_{2}$ is freely released into the atmosphere, contrary to conventional MWFs, which are stored back into the reservoir. Therefore, the cost assessment is needed to economically justify the use of $\mathrm{LCO}_{2}$ based machining processes. In addition, $\mathrm{CO}_{2}$ concentration should be monitored, as the workplace $\mathrm{CO}_{2}$ levels in surrounding air should not exceed $0.5 \%$ concentration for 8-hour exposure time according to Occupational Safety and Health Administration (OSHA) [19].

Contrary, total elimination of MWFs may be hard to reach, especially when considering their benefits when delivered to the cutting zone under high pressure. In continuous cutting, such as turning or drilling, long chips can be problematic especially when machining difficult-to-cut materials. In conventional High Pressure Jet Assisted Machining (HPJAM), one or more focused and high-energetic coolant jets are delivered into the chip-forming zone, thus increasing the productivity [20] to [22], tool life [15], [20] to [23] and chip breakability [24] and [25]. Two main high pressure MWFs supply variants are shown in Fig. 2; blue arrow indicate the high pressure MWFs supply: a) between chip and rake face, b) between workpiece and flank face, or combination of a) and b) is also in use [26].

Despite the positive effects of HPJAM, the industrial application is not yet wide spread, due to: (i) High energy consumption [21], [23], and [24]; (ii) Surface anomalies by interaction between broken chips and machined surface [22], [24] and [25]; (iii)

Unpredictable behaviour of broken chips [22] and [23] and (iv) Unknown potential in wider scope [15] and [23]. Moreover, in practical applications HPJAM is still limited to roughing processes. The extension to finishing processes is desired, but currently challenging due to stated reasons. In order to address these issues, pulsating HPJAM has been proposed in collaboration with WZL, RWTH Aachen, Germany [27]. Principle of operation is presented in Fig. 3. By pulsating the high pressure jet, the high pressure is achieved only at short intervals when chip breakage and removal is required. In the meantime, the pressure is reduced to lower values only to provide the necessary cooling and lubrication with considerable savings in energy consumption. Presented pulsating HPJAM concept represents novelty in the field, wherein only few scientific studies have been found, yet all of them based on pulsating MQL [28] to [34]. Pulsating MQL does not have the same pressure nor flow rate (jet force) compared to pulsating HPJAM and therefore these two cannot be directly comparable.

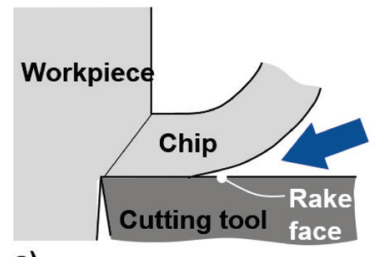

a)

Fig. 2. MWFs supply: a) between chip and rake face; b) between workpiece and flank face

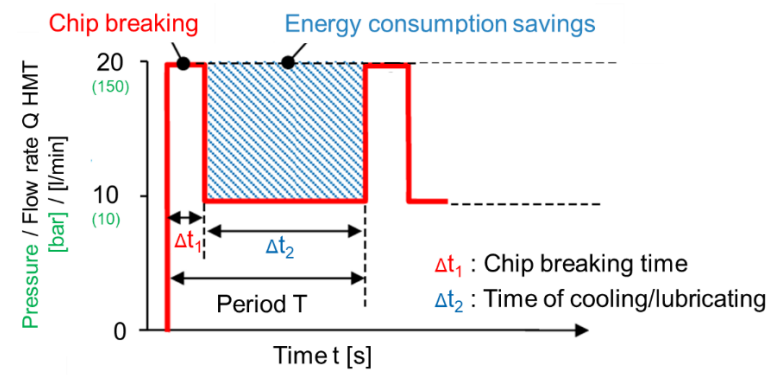

Fig. 3. Pulsating high-pressure supply of MWFs - basic principle

Both presented machining technologies are advanced with great research potential. In addition, both advanced principles are currently holding the status of patent pending [9] and [27]. This paper presents their performance. Therefore, the goal of this study is to: (i) Evaluate machining performance on difficult-to-cut materials; (ii) Perform cost assessment and (iii) Perform risk assessment. 


\section{EXPERIMENTAL PROCEDURE}

\section{1 $\mathrm{LCO}_{2}+\mathrm{MQL}$ Machining Experiments}

Milling experiments were performed on $\mathrm{CNC}$ machining centre Doosan NX 6500 II with through tool delivery. Workpiece material was Ti-alloy Ti-6Al$4 \mathrm{~V}(\alpha+\beta)$. Prototype milling cutter with four $0.4 \mathrm{~mm}$ nozzles for $\mathrm{LCO}_{2}+\mathrm{MQL}$ mixture was used. The flow rates were $12 \mathrm{~kg} / \mathrm{h}$ for $\mathrm{LCO}_{2}$ and $60 \mathrm{ml} / \mathrm{h}$ for MQL oil. The principle of mixing oil into the stream of $\mathrm{LCO}_{2}$ is shown in Fig. 4a. More detailed explanation of the principle can be found in [9]. Cutting parameters are found in Fig. 5. For tool life comparison, $\mathrm{LCO}_{2}$ + MQL principle was directly compared to flood lubrication, where the emulsion Blaser B-Cool 9665 with $7 \%$ concentration was used. Same parameters and tools were used in both cases and the tool wear was monitored at specified time intervals. After the experiments, the chips were collected to study their morphology. At the same time, $\mathrm{CO}_{2}$ levels in the air were monitored using Witt-Gasetechnik RLA 100 air monitor. The measurements were taken in close proximity of $\mathrm{CNC}$ command module, where the operator is usually located when operating the machine. Due to the nature of the expanding $\mathrm{LCO}_{2}$,
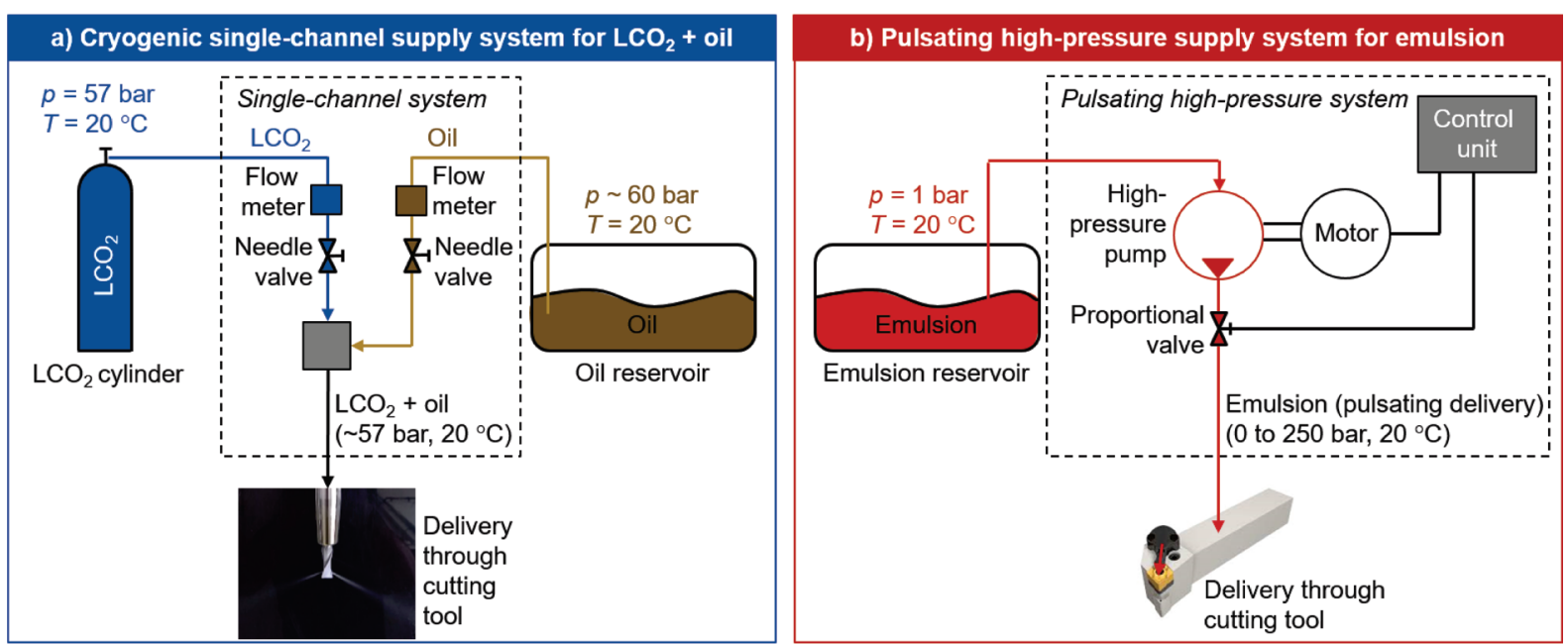

Fig. 4. Schematic setups a) for single-channel supply of $\mathrm{LCO}_{2}+\mathrm{MQL}$; and b) pulsating HPJAM

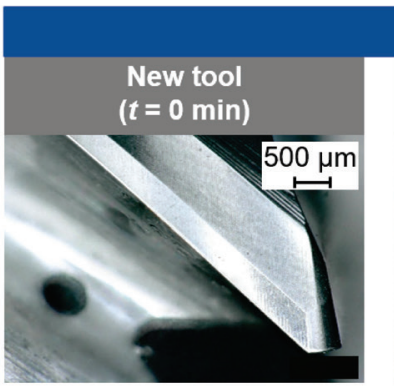

\section{Cryogenic machining (milling)}
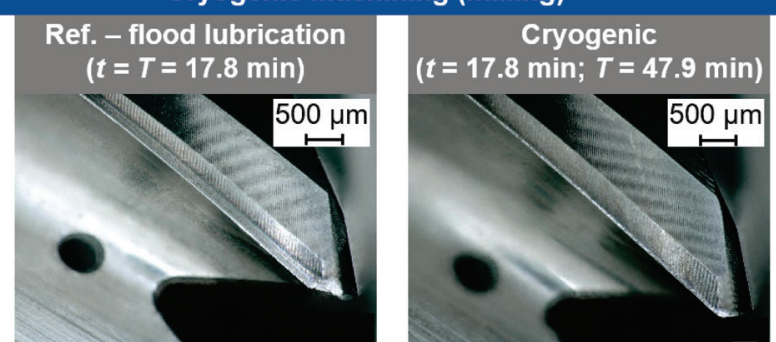

Cutting tool:

Full body milling cutter

$d=8 \mathrm{~mm}$

$z=4$

Cutting parameters:

$\mathrm{v}_{\mathrm{c}}=60 \mathrm{~m} / \mathrm{min}$

$f_{\mathrm{z}}=0.08 \mathrm{~mm} / \mathrm{t}$

$a_{p}=8 \mathrm{~mm}$

$a_{e}=2.4 \mathrm{~mm}$

Workpiece material:

Ti-6Al-4V $(\beta)$

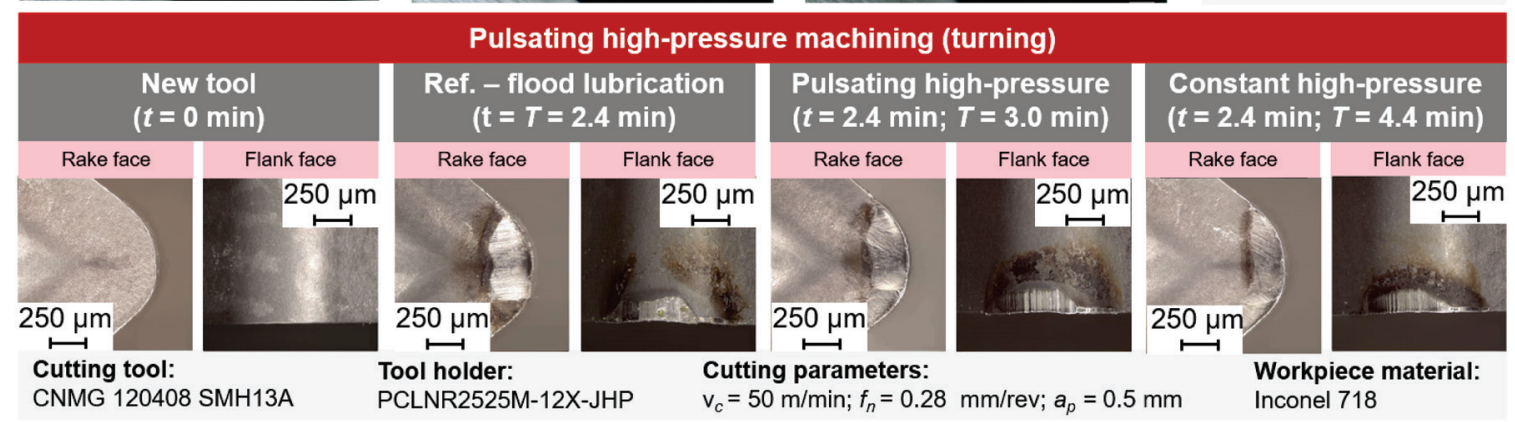

Fig. 5. Tool wear in cryogenic machining and pulsating HPJAM ( $t$ - time; $T$ - tool life) 
oil droplets are atomized to about $10 \mu \mathrm{m}$ in diameter [9] and the monitoring of sufficient ventilation is necessary for risk assessment. Power consumption of single-channel supply system of $\mathrm{LCO}_{2}+\mathrm{MQL}$ was also monitored using multifunction instrument PowerQ MI2492.

\subsection{Pulsating HPJAM Experiments}

Turning experiments were performed on $\mathrm{CNC}$ lathe Mori Seiki SL153. Cutting parameters are found in Fig. 5. Inconel 718 was used as workpiece material and Sandvik CNMG 11408 SMH13A cutting inserts as tools. Iscar tool holder with high pressure nozzle (up to 300 bar, $d=1 \mathrm{~mm}$ ) was used to guide the jet between the chip and the rake face (Fig. 2a). Similar as for cryogenic machining, pulsating HPJAM was compared to conventional flood lubrication (Blaser B-Cool 9665, $7 \%$ ) and conventional HPJAM. For flood lubrication, emulsion was supplied through standard $5 \mathrm{~mm}$ pipe under the pressure of 1 bar. Pulsating parameters were: high pressure 200 bar, low pressure 1 bar, pulsating frequency $5 \mathrm{~Hz}$, (high pressure pulse time $60 \mathrm{~ms}$, low pressure pulse time $140 \mathrm{~ms}$ ). For conventional HPJAM pressure was set to same but constant value of 200 bar. Schematic presentation of the system is shown in Fig. 4b. Measured were: tool wear, chip morphology and overall power consumption using PowerQ MI2492 multifunction instrument. Emulsion atomization in machining area was also observed due to jet's high preossure. This has been evaluated based on visual observation of time needed for mist elimination.

\section{RESULTS AND DISCUSSION}

\subsection{Tool Life Experiments}

For cryogenic milling, critical flank face wear was achieved after 47.9 minutes, which is a great improvement over the time of 17.8 minutes when using flood lubrication. The criteria for worn tool was maximum flank face wear $V B_{\max }$ of $200 \mu \mathrm{m}$. It was also observed that the tool wear mechanism in flood lubrication was edge chipping, whereas in cryogenic machining main wear mechanism was abrasion that was evenly distributed between all four cutting edges of an end mill (Fig. 5).

Pulsating high-pressure turning experiments with same tool life criteria resulted in tool life of 3.2 minutes was reached. In comparison, tool life for flood lubrication was 2.4 minutes and for conventional highpressure machining 4.4 minutes. Additionally to the flank face wear, crater wear was also observed (Fig. 5). The main tool wear mechanism was abrasion, as this coincides with the machining of Inconel 718 [21].

For both techniques, every experiment was conducted two times and the average value was calculated, while the difference between the values was within $5 \%$.

\subsection{Chip Morphology}

Cryogenic machining produced similar chips to conventional flood lubrication throughout all experiments, as seen in Fig. 6. As there are no visible differences in shape and color, we can assume the cryogenic machining provides sufficient cooling and lubrication, which are critical properties for sustainability of cryogenic machining.

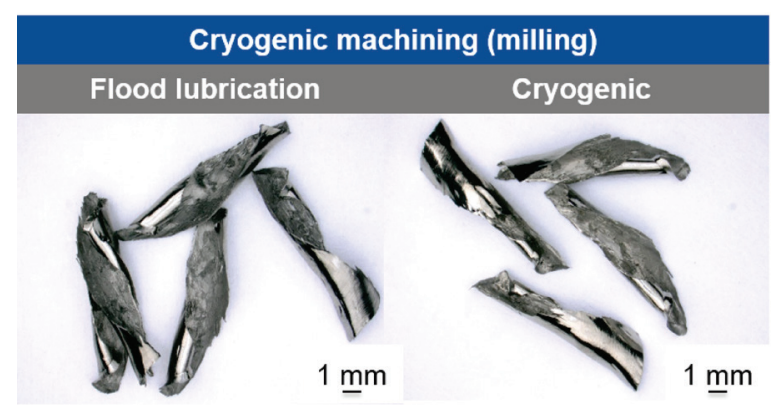

Fig. 6. Chip morphology by using flood lubrication versus cryogenic machining

On the other side, pulsating high-pressure had strong influence on chip morphology (Fig. 7). In conventional flood lubrication, the chips were long tubular chips. Shorter tubular chips were observed with the use of constant high-pressure machining, while the most suitable chips were produced by using pulsating HPJAM. Inconel is notorious for workhardening and very elastic chips that are hard to break. In conventional HPJAM, sufficient pressure of coolant delivery must be achieved to break the chips [22]. From Fig. 7 we can see that the chips under constant high-pressure conditions had smaller up-curling radius compared to flood lubrication due to the high energy of the jet. However, the pressure was still not sufficient to achieve constant chip breakage. By maintaining the same pressure, but employing pulsating principle, chip breakage occurred controlably, with chips having much shorter and consistent overall length. The change in chip up-curling radius due to the impulse of the pulsating jet can be seen on the lower right side of Fig. 7. These differences imply that higher pressure is not 
necessarily needed to improve chip breakability; it is also important to consider its dynamic ability of sudden impact on chip deformation and consequently, chip breakage. Additionally, the cost savings are evident as sufficient pressure of coolant supply may be lower as well as overall flow rate that is closely related to the power of the pump.

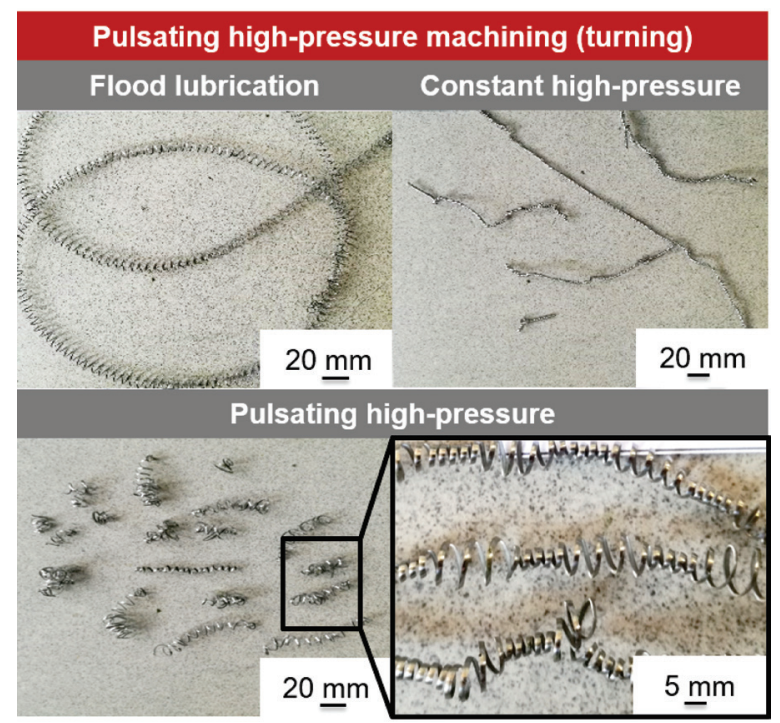

Fig. 7. Chip morphology by using flood lubrication versus pulsating HPJAM

Chip morphology is especially important in finishing processes. A stable process is always desired and the control over chips is a part of that. In finishing processes, the product has the greatest added value and errors in manufacturing should be avoided. In finishing turning, long chips can damage the machined surface or in worst case damage the operator or machine tool. To gain control over chip breakage, pulsating HPJAM can show great benefits while also discarding some of the disadvantages of the conventional HPJAM such as high energy consumption, surface anomalies due to chip-workpiece collisions at higher pressures and higher costs related to the equipment needed to produce higher pressure.

\subsection{Cost Assessment}

In machining, total manufacturing cost of a produced part is usually a sum of manufacturing overheads (salaries, property taxes, rents, machine tools, depreciation, etc.), administrative overheads (salaries, travel costs, legal fees, etc.), direct labor costs and material costs (direct and indirect). For the purpose of this paper, the cost assessment is focused on indirect material cost as we assume that the manufacturing and administrative overheads as well as direct labour and material costs are constant, regardless of the cooling and lubrication technique.

Indirect material costs in this case are related to the purchase, maintenance and disposal costs of MWFs (emulsion), $C_{M W F}$, to the purchase of $\mathrm{LCO}_{2}$ and MQL oil, $C_{C R Y O}$, to the electrical consumption, $C_{E L}$, and to the cutting tool costs, $C_{T O O L}$. The cost of the system purchase and installation is separately included $\left(C_{S Y S}\right)$. In addition, $t_{T O O L}$ presents tool lifetime as described in section 2.1, where the time of 5 minutes has been added as a tool change time. For turning operation, this combined time has been additionally multiplied by 4 , as there are four usable cutting edges on each insert. 3840 working hours per year (20 days, two working shifts) were considered for this calculation; working hours are denoted as $t_{\text {WORK }}$. Down time of the machine was not included in this study. Cryogenic consumptions, $Q_{C R Y O}$, are the flow rates of both $\mathrm{LCO}_{2}$ and MQL oil as mentioned in section 1.1, and cryogenic costs, $C_{C R Y O}$, are based on their market price.

Measured electrical power in $\mathrm{kW}$ was multiplied by $0.20 € / \mathrm{kWh}$, the approximate European average price. Average power consumption when cryogenic machining was approximately $0.4 \mathrm{~kW}$ due to innovative and patented principle of using the pressure energy of $\mathrm{LCO}_{2}$ to inject the oil in its flow [9]. Flood lubrication used on average $0.75 \mathrm{~kW}$, conventional high-pressure $8 \mathrm{~kW}$ and pulsating high-pressure $3 \mathrm{~kW}$ of electricity. The energy consumption ratio of 0.38 between pulsating high-pressure and conventional high-pressure is close to theoretical ratio of 0.43 , calculated by using high and low pressure pulse times of $60 \mathrm{~ms}$ and $140 \mathrm{~ms}$, respectively.

The total cost, $C_{T O T}$, for the first year of running, based on Fig. 8, can be expressed as:

$$
\begin{aligned}
C_{T O T}= & C_{M W F}+C_{S Y S}+ \\
& \left(C_{E L}+C_{T O O L} / t_{T O O L}+C_{C R Y O} \cdot Q_{C R Y O}\right) \cdot t_{W O R K} .
\end{aligned}
$$

Total annual costs for both advanced machining methods in comparison to conventional techniques are shown in Fig. 9. It can be observed that cost reduction of $44.7 \%$ is possible by the implementation of cryogenic machining instead of conventional flood lubrication. The difference would be even greater in favor of cryogenic machining if costs related to part cleaning due to emulsion contamination were considered. According to Eq. (1), the most influential factor is the tool cost, especially due to short tool life as a result of machining of difficult-to-cut material. 


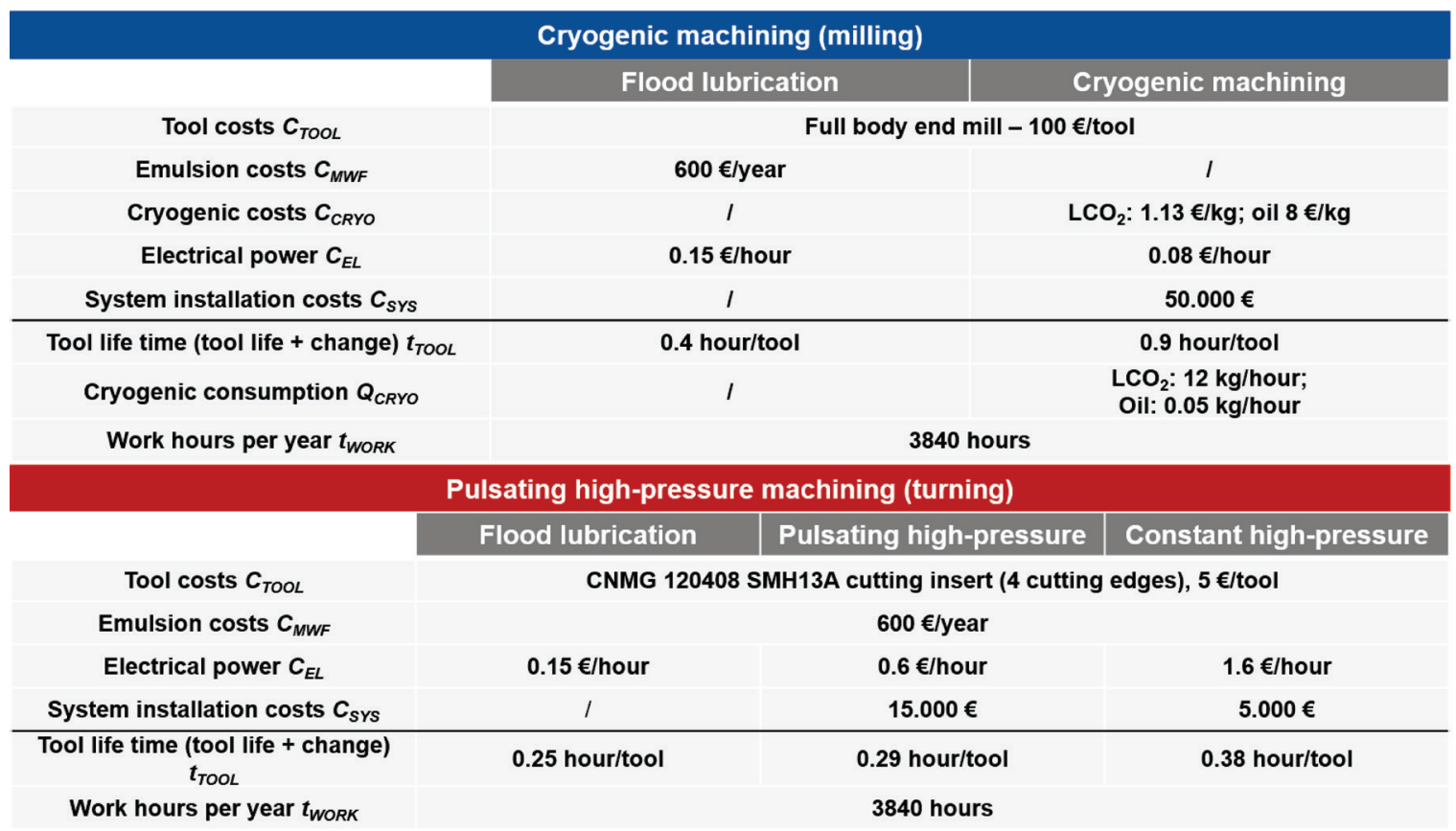

Fig. 8. Operational costs for cryogenic machining and pulsating HPJAM

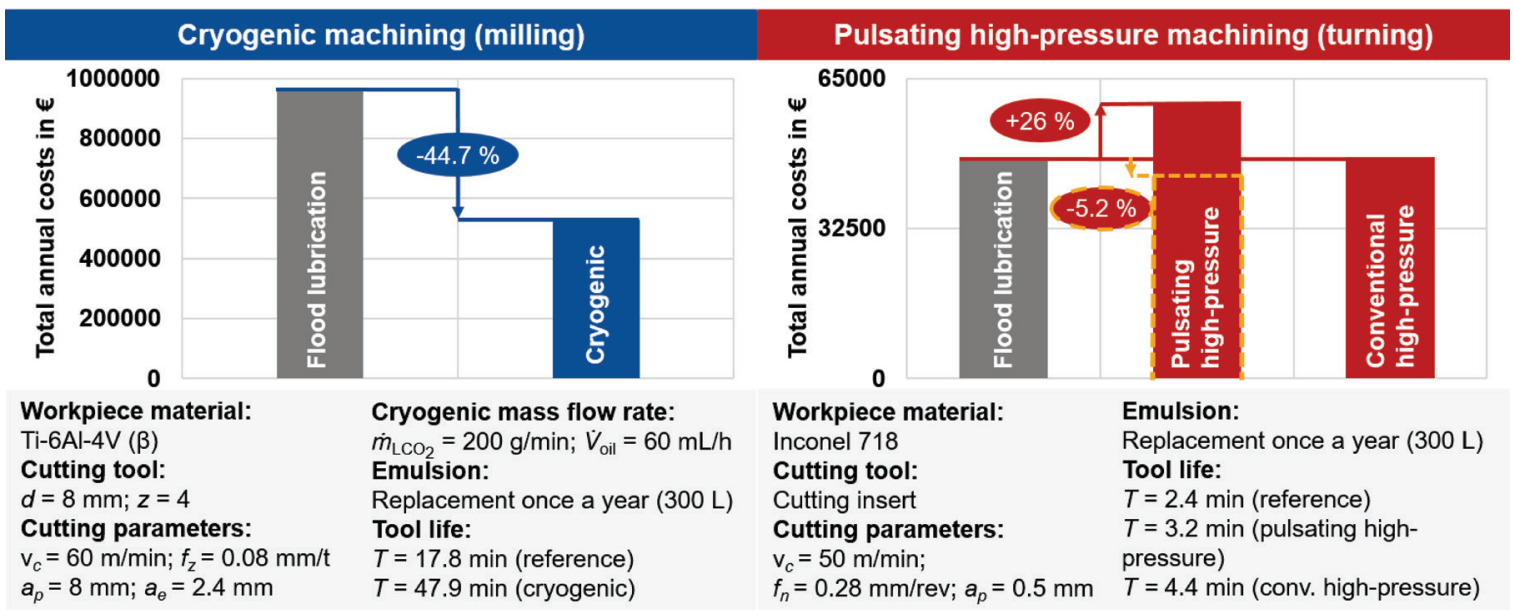

Fig. 9. Calculation of total annual costs for cryogenic machining and pulsating HPJAM

The second most influential factor is the cost of $\mathrm{LCO}_{2}$. As it is non-renewable, its consumption should be optimised in order to achieve optimal cutting temperature at lowest possible flow rate, as also discussed in [7].

On the other side, pulsating high-pressure showed highest costs between all three principles; with the $26 \%$ increasement in costs over the flood lubrication. The tool cost is by far the most important factor of the total annual cost. Conventional highpressure costs were almost identical to those of flood lubrication. However, the system installation costs are also included in the calculation. Assuming little to no maintenance to high-pressure systems, the cost savings would be evident on the $2^{\text {nd }}$ year of use. If the system installation costs are excluded, the use of pulsating high-pressure technique results in roughly $5.2 \%$ reduced annual costs compared to flood lubrication, shown with yellow dashed line in Fig. 9. The use of conventional high-pressure results in $9.2 \%$ reduction if installation costs are not considered.

Although the initial costs for installation of pulsating high-pressure system are high, apart from longer tool life, other benefits can be visible. One 
such example is shown in Fig. 10 where turning of AISI 4142 alloy under flood lubrication led to long, continuous chips which wrapped around the workpiece, causing the damage to the workpiece and production delay. The main advantage of pulsating principle, over conventional high-pressure machining, is the ability to precisely control the chip length. If chips are tool short they can partially absorb the energy of the high-pressure jet and fly with high velocity in unpredictable directions. This means that there is a high probability they will collide with the workpiece, causing collision anomalies on the already machined surface. This can be avoided by pulsating, so the chips have time to reach critical length at which they present the least risk to overtake high speed from emulsion jet.

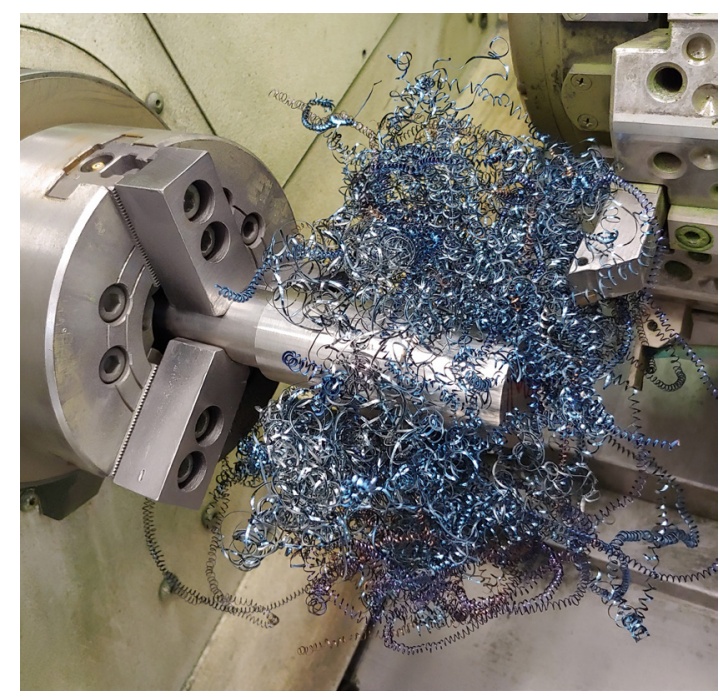

Fig. 10. Continuous chips wrapped around workpiece when turning AISI4142 alloy

\subsection{Risk Assessment}

During cryogenic machining, $\mathrm{CO}_{2}$ levels in the air, near vicinity of the machining area, did not exceed the OSHA prescribed value of $0.5 \%$ (Fig. 11). However, it was observed that adequate suction and air filtration is needed to remove oil mist from the machining area. As described in section 1.1, $\mathrm{LCO}_{2}$ atomizes the oil into small particles. The current OSHA prescribed maximum level of oil mist in air is $5 \mathrm{mg} / \mathrm{m}^{3}$ as an 8 -hour time-weighted average [19]. Workplace exposure to MWFs can lead to various health problems such as dermatitis, respiratory problems or even several types of cancer if the exposure is long-term [35]. Workplace measurements of the oil mist in air concentration are still scarce and further work is needed. By using the
$\mathrm{LCO}_{2}+\mathrm{MQL}$ principle, the machining area should be an enclosed space with sufficient suction and ventilation to remove as much oil mist as possible before human intervention into the machining area occurs (workpiece clamping, tool replacement, etc.).

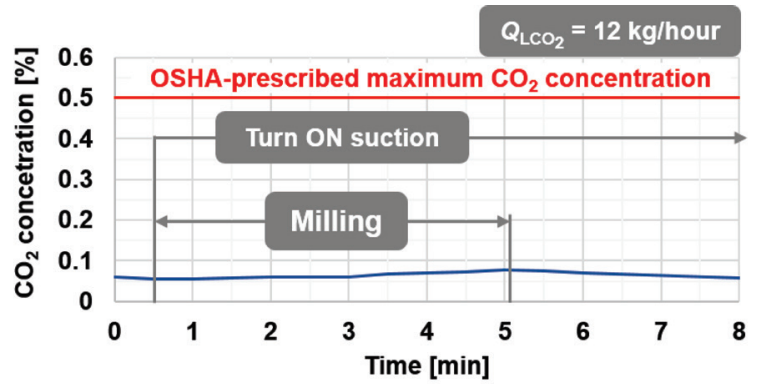

Fig. 11. Cryogenic machining: $\mathrm{CO}_{2}$ in air concentration at $\mathrm{CNC}$ command module

Using the high-pressure cooling and lubrication principle results also in emulsion atomization. It has been observed that the total time for mist elimination after machining has been reduced by approx. 30 $\%$ when using pulsating high-pressure principle, compared to conventional high-pressure method where demisting happened after approx. 20 seconds. This time was determined solely on visual examination of the machining area through the door window. Further work with precise instruments to measure workplace air quality is needed. In conventional highpressure machining short chips with high velocity present a threat to the operator if machining area is not an enclosed space. On the other side, continuous chips as shown in Fig. 10 are also dangerous due to sharp edges and unpredictable behaviour. Thus, pulsating high-pressure principle may reduce the risk of workplace injury due to unsuitable chips.

\section{CONCLUSIONS}

Two advanced machining technologies, i.e. cryogenic machining using lubricated $\mathrm{LCO}_{2}$ and pulsating HPJAM, were presented and their sustainability was estimated over: (i) tool life; (ii) chip morphology; (iii) cost assessment and (iv) risk assessment. Main conclusions can be drawn, as follows.

- Cryogenic machining using $\mathrm{LCO}_{2}+\mathrm{MQL}$ and pulsating HPJAM exhibit prolonged tool life of $169 \%$ and $33 \%$, respectively, in comparison to conventional flood lubrication.

- No major difference in chip morphology was observed in cryogenic machining compared to flood lubrication. On the other hand, pulsating 
HPJAM offered superior control over chip shape and size compared to both conventional flood lubrication and HPJAM.

- Transition to cryogenic machining reflects in 44.7 $\%$ lower running costs compared to conventional flood lubrication due to significantly longer tool life $(+169 \%)$. Both conventional and pulsating HPJAM offer lower running costs by $9.2 \%$ and $5.2 \%$, respectively, compared to conventional flood lubrication.

- Cryogenic machining represents risk-free advanced machining technology if suitable safety measurements are met, such as enclosed machining area and appropriate ventilation. In such running conditions, $\mathrm{CO}_{2}$ concentration near the machine tool is significantly lower than OSHA-prescribed maximum concentration. For pulsating HPJAM, approx. $30 \%$ time reduction for mist elimination was achieved; however, bigger risk reduction impact using pulsating technology presents ability to precisely control the chip length. Moreover, future work will feature mist analysis (mist size and distribution) in the workplace zone for both cryogenic and pulsating high-pressure technologies.

\section{ACKNOWLEDGEMENTS}

The work was funded by the Slovenian Research Agency (ARRS) via research project L2-8184 and research program P2-0266.

\section{REFERENCES}

[1] Klocke, F., Eisenblätter, G. (1997). Dry cutting. CIRP Annals, vol. 42, no. 2, p. 519-526, D0l:10.1016/S0007-8506(07)60877-4.

[2] Byrne, G., Dornfeld, D.A., Denhkena, B. (2003). Advancing cutting technology. CIRP, vol. 52, no. 2, p. 483-507, DOI:10.1016/S0007-8506(07)60200-5.

[3] Weinert, K., Inasaki, I., Sutherland, J.W., Wakabayashi, T. (2004). Dry machining and minimum quantity lubrication. CIRP Annals, vol. 53, no. 2, p. 511-537, D0l:10.1016/S00078506(07)60027-4.

[4] Jawahir, I.S., Attia, H., Biermann, D., Duflou, J., Klocke, F., Meyer, D., Newman, S.T., Pušavec, F., Putz, M., Rech, J., Schulze, V., Umbrello, D. (2016). Cryogenic manufacturing processes. CIRP Annals, vol. 65, no. 2, p. 713-736, DOI:10.1016/j.cirp.2016.06.007.

[5] Pušavec, F., Krajnik, P., Kopač, J. (2010). Transitioning to sustainable production - part I: application on machining technologies. Journal of Cleaner Production, vol. 18, no. 2, p. 174-184, D0I:10.1016/j.jclepro.2009.08.010.

[6] Courbon, C., Pušavec, F., Dumont, F., Rech, J., Kopač, J. (2013). Tribological behavior of Ti6AI4V and Inconel 718 under dry and cryogenic conditions-Application to the context of machining with carbide tools. Tribology International, vol. 66, p. 72-82, D0l:10.1016/j.triboint.2013.04.010.

[7] Pušavec, F., Grguraš, D., Koch, M., Krajnik, P. (2019). Cooling capability of liquid nitrogen and carbon dioxide in cryogenic milling. CIRP Annals, vol. 68, no. 1, p. 73-76, D0l:10.1016/j. cirp.2019.03.016.

[8] Kramer, A. (2015). Gestaltungsmodell der kryogenen Prozesskühlung in der Zerspanung. Apprimus Verlag, RWTH Aachen University, Aachen. (in German)

[9] Grguraš, D., Sterle, L., Krajnik, P., Pušavec, F. (2019). A novel cryogenic machining concept based on a lubricated liquid carbon dioxide. International Journal of Machine Tools and Manufacture, vol. 145, ID 103456, D0l:10.1016/j. ijmachtools.2019.103456.

[10] Cordes, S., Hübner, F., Schaarschmidt, T. (2014). Next generation high performance cutting by use of carbon dioxide as cryogenics. Procedia CIRP, vol. 14, p. 401-405, D0I:10.1016/j.procir.2014.03.091.

[11] Jerold, B.D., Kumar, M.P. (2012). Experimental comparison of carbon-dioxide and liquid nitrogen cryogenic coolants in turning of AISI 1045 steel. Cryogenics, vol. 52, no. 10, p. 569574, D0l:10.1016/j.cryogenics.2012.07.009.

[12] Bergs, T., Pušavec, F., Koch, M., Grguraš, D., Döbbeler, B., Klocke, F. (2018). Investigation of the solubility of liquid $\mathrm{CO}_{2}$ and liquid oil to realize an internal single channel supply in milling of Ti6Al4V. Procedia Manufacturing, vol. 33, p. 200207, D0I:10.1016/j.promfg.2019.04.024.

[13] Hanenkamp, N., Amon, S., Gross, D. (2018). Hybrid supply system for conventional and $\mathrm{CO}_{2} / \mathrm{MQL}$-based cryogenic cooling. Procedia CIRP, vol. 77, p. 219-222, D0l:10.1016/j. procir.2018.08.293.

[14] Patil, N.G., Asem, A., Pawade, R.S., Thakur, D.G., Brahmankar, P.K. (2014). Comparative study of high speed machining of Inconel 718 in dry condition and by using compressed cold carbon dioxide gas as coolant. Procedia CIRP, vol. 24, p. 8691, D0I:10.1016/J.procir.2014.08.009.

[15] Cayli, T., Klocke, F., Lung, D. (2014). The Influence of highpressure lubricoolant supply variant on cutting performance in turning of 42CrMo4+QT. Advances in manufacturing technology: 11th International Conference High Speed Machining, Praque.

[16] Supekar, S.D., Clarens, A.F., Stephenson, D.A., Skerlos, S.J. (2012). Performance of supercritical carbon dioxide sprays as coolants and lubricants in representative metalworking operations. Journal of Materials Processing Technology, vol. 212, no. 12, p. 2652-2658, D0l:10.1016/j. jmatprotec.2012.07.020.

[17] Wika, K.K., Litwa, P., Hitchens, C. (2019). Impact of supercritical carbon dioxide cooling with minimum quantity lubrication on tool wear and surface integrity in the milling of AISI 304L stainless steel. Wear, vol. 426-427, p. 426-427, D0I:10.1016/j.wear.2019.01.103.

[18] Augspurger, T., Koch, M., Klocke, F., Döbbeler, B. (2019). Investigation of transient temperature fields in the milling cutter under $\mathrm{CO}_{2}$ cooling by means of an embedded thermocouple. Procedia CIRP, vol. 79, p. 33-38, D0l:10.1016/j. procir.2019.02.007. 
[19] United States Department of Labor. Occupational Safety and Health Administration (OSHA), from https://www.osha.gov/ dsg/annotated-pels/tablez-1.html, accessed on 2019-09-19.

[20] Klocke, F., Lung, D., Kramer, A., Cayli, T., Sangermann, H. (2013). Potential of modern lubricoolant strategies on cutting performance. Key Engineering Materials, vol. 554-557, p. 2062-2071, DOl:10.4028/www.scientific.net/KEM.554557.2062.

[21] Pušavec, F., Kramar, D., Kenda, J., Krajnik, P., Kopač, J. (2009). Experimental analysis of sustainability in machining of Inconel 718. Proceedings of the $42^{\text {nd }}$ CIRP Conference on Manufacturing Systems.

[22] Courbon, C., Kramar, D., Krajnik, P., Pušavec, F., Rech, J., Kopač, J. (2009). Investigation of machining performance in high-pressure jet assisted turning of Inconel 718: An experimental study. International Journal of Machine Tools and Manufacture, vol. 49, no. 14, p. 1114-1125, D0l:10.1016/j. ijmachtools. 2009.07.010.

[23] Klocke, F. (2011). Manufacturing Processes 1: Cutting. Springer Verlag, RWTH Aachen University, Aachen.

[24] Sangermann, H. (2013). Hochdruck-Kühlschmierstoffzufuhr in der Zerspanung. Apprimus Verlag, RWTH Aachen University, Aachen. (in German)

[25] Cayli, T., Klocke, F., Veselovac, D. (2015). Effect of Jet Guidance Geometries in turning of aerospace materials with High-Pressure Lubricoolant Supply. RWTH Aachen University, Aachen, from https://core.ac.uk/download/pdf/36662783. pdf, accessed on 2019-09-19.

[26] Cayli, T. (2017). Surface Anomalies in Turning of Difficult-ToCut Materials with High-Pressure Coolant Supply. Apprimus Verlag, RWTH Aachen University, Aachen.

[27] Cayli, T., Klocke, F., Döbbeler, B., Pušavec, F., Bernstorff, O. (2016). Patent applied DE 102016119852.8 Verfahren und Anordnung zur Zufuhr eines Kühlfluids hin zu einer Bearbeitungsstelle eines metallischen Werkstücks. RWTH Aachen University, Aachen. (in German)

[28] Varadarajan, A.S., Philip, P.K., Ramamoorthy, B. (2002). Investigations on hard turning with minimal cutting fluid application (HTMF) and its comparison with dry and wet turning. International Journal of Machine Tools and Manufacture, vol. 42, no. 2, p. 193-200, D0l:10.1016/S08906955(01)00119-5.

[29] Thepsonthi, T., Hamdi, M., Mitsui, K. (2009). Investigation into minimal-cutting-fluid application in high-speed milling of hardened steel using carbide mills. International Journal of Machine Tools and Manufacture, vol. 49, no. 2, p. 156-162, D0l:10.1016/j.jjmachtools.2008.09.007.

[30] Zhang, S., Liao, Z., Chen, D. (2011). Pulsed cutting fluid improved machining process. Journal of the Chinese Institute of Engineers, vol. 34, no. 2, p. 233-237, D0l:10.1080/02533 839.2011.565584.

[31] Bashir, M.A., Mia, M., Dhar, N.R. (2015). Effect of pulse jet MQL in surface milling of hardened steel. Journal of Mechanical Engineering, vol. 45, no. 2, p. 67-72, Dol:10.3329/jme. v45i2.28118.

[32] Gnanadurai, R.R., Varadarajan, A.S. (2016). Investigation on the effect of cooling of the tool using heat pipe during hard turning with minimal fluid application. Engineering Science and Technology, an International Journal, vol. 19, no. 3, p. 1190-1198, D0I:10.1016/j.jestch.2016.01.012.

[33] Gnanadurai, R.R., Varadarajan, A.S. (2014). Investigation on the effect of an auxiliary pulsing jet of water at the top side of chip during hard turning of AISI 4340 steel with minimal fluid application. International Journal of Precision Engineering and Manufacturing, vol. 15, no. 7, p. 1435-1441, D0l:10.1007/ s12541-014-0488-5.

[34] Sam Paul, P., Varadarajan, A.S., Gnanadurai, R.R. (2016). Study on the influence of fluid application parameters on tool vibration and cutting performance during turning of hardened steel. Engineering Science and Technology, an International Journal, vol. 19, no. 1, p. 241-253, D0l:10.1016/j. jestch.2015.07.017.

[35] Wlaschitz, P., Höflinger, W. (2007). A new measuring method to detect the emissions of metal working fluid mist. Journal of Hazardous Materials, vol. 144, no. 3, p. 736-741, D0I:10.1016/j.jhazmat.2007.01.104. 